\title{
Editorials
}

This is the final issue of the fournal of Accident and Emergency Medicine to appear under my editorship. Peter Driscoll and Jim Wardrope have been appointed as editors and I wish them every success.

As I head towards the sunset, I must express my thanks to all those who have been part of the editorial team during my tenure. Without wishing to be too Oscar-esque, there are key individuals without whom none of this would have been possible.

I am grateful to Richard Smith and Alex Williamson for providing the opportunity for the journal to join the prestigious ranks of BMJ Specialist Journals. Valerie Crean and Andrea Horgan have provided masterful management skills.

The skills of the technical editors should never ever be under-estimated - this verdict is evidence-based having spent many hours in the past proof reading manuscripts only to fail to spot the typos! I have been extremely fortunate to have had the experience and expertise of Oliver Brooke initially and latterly Sue Heels in this role.

The appropriate phrase to express my gratitude to Kathryn Sims, editorial assistant, remains just outside my grasp. She has been absolutely outstanding and pivotal as the principal point of contact at the journal. Kathryn has brilliantly managed my idiosyncrasies and those difficult phone calls sometimes received from authors whose papers have been rejected. Superlatives seem inadequate.

This is a quintessential team effort and it would have been simply impossible to function without the unfailing support and contribution of the associate editors and editorial board. My thanks also to the squad of reviewers of papers for the journal whose enthusiasm and commitment have been superb.

It has been a privilege and pleasure to serve as editor during these past five years. I believe that the journal has continued to fulfil the potential made possible by previous editors. This evolution will continue and the journal has an exciting future as one of the leading international publications in emergency medicine.

\section{bestbets.org: Odds on favourite for evidence in emergency medicine reaches the world wide web}

This edition sees the second anniversary of the first publication of best evidence topic reports (BETs) from Manchester Royal Infirmary, ${ }^{1}$ the publication of the first ever "guest" BETs and the launch of the bestbets web site.

The BETs were designed in 1997 as a method for appraising real clinical questions using published evidence. ${ }^{2}$ The BETs were never meant to be systematic reviews. They are a method of evidence retrieval, evaluation and collation easily achievable by busy emergency physicians. Although originally used to influence practice locally, publication in the $\mathcal{F} A E M$ has disseminated the information to a much wider audience. The BETs were based on the critically appraised topics (CATs) developed by Sackett et al. ${ }^{34}$ CATs usually use one or two high qual-

The patient

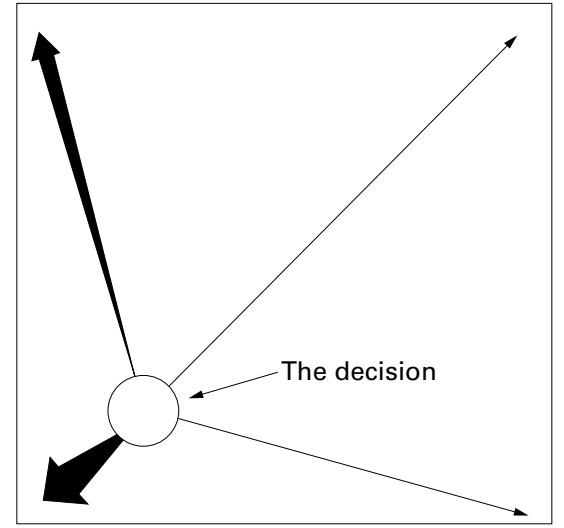

The evidence

The cost

Physician skill

Figure 1 Factors affecting the clinical decision. ity papers to answer a specific question; this approach has been adopted in other emergency medicine journals. ${ }^{5}$ The BETs extend the model by including lower quality evidence where no high quality evidence exists as the practising clinician needs to know "what evidence is available?" rather than just "are there any high quality papers on the subject?"

This need for inclusion of lower ranking evidence is particularly marked in emergency medicine where the subject matter is vast and the research base is frequently poor. Patients still need to be treated and judgments must be made on whatever evidence is available. The BETs system makes the information explicit (whatever its level) so that decisions can be informed ones. An interesting side effect of the critical analysis of the research base has been a realisation of just how frequently established practice is based on little to nothing. This has led to questioning of current practice and the gestation of many research projects.

Other centres and individuals have shown a great deal of interest in producing their own BETs. This sounds a simple thing to organise but actually presents problems in terms of both quality assurance and duplication of effort (over $200 \mathrm{BETs}$ are currently registered as complete or in progress and only 61 have been published so far). The Best BETs web site at http://www.bestbets.org has been developed to facilitate the process of BET production and publication by allowing anyone to register BET topics online. BETs should be registered as three part questions, and, once registered, topics will be held for six months. This time should be ample for completion of the BET. By registering and developing BETs through the web site we hope to encourage and help in the publication of "guest" BETs alongside those from the Manchester Royal Infirmary. The first of these "guest "BETs appear in this edition. 
New evidence is always appearing and BETs can only be as up to date as the date on which the search was last executed. The search strategies have always been an explicit part of the BETs so as to allow others to check and update the evidence. The web site offers an opportunity to continuously update BETs and it is intended that this will be done at a minimum of six monthly intervals.

Local and national interest in the BETs has suggested that they are widely read. However, determining if they result in a change in practice is difficult. This will be the acid test in determining whether all the effort has been worthwhile and further work on this question is currently in progress.

In clinical practice decisions regarding individual patient care are rarely made purely on the basis of the evidence, however good it might be. Doctors treat patients not papers, have limited budgets and differing skill levels. What is actually done will depend upon the relative weightings of all these factors as shown in figure 1.

Defining the evidence is an essential step in allowing clinical decisions to be made rationally. Ultimately, it is hoped that the BETs will address most of the important issues in our practice, producing the evidence for what we do. The list of unanswered questions is clearly enormous and if the desire to define the evidence on which we base our practice is to succeed, many people will need to be involved in answering them.

We look forward to hearing from you.

KEVIN MACKWAY-JONES SIMON CARLEY

Department of Emergency Medicine, Manchester Royal Infirmary

1 Carley SD, Mackway-Jones K, Jones A, et al. Moving towards evidence based emergency medicine: use of a structured critical appraisal journal club. F Accid Emerg Med 1998;15:220-2

2 Mackway-Jones K, Carley SD, Morton RJ, et al. The best evidence topic report: a modified CAT for summarising the available evidence in emergency medicine. f Accid Emerg Med 1998;15:222-6.

$3 \mathrm{http} / / /$ cebm.jr2.ox.ac.uk/docs/cats/catabout.html

4 Sackett DL, Richardson WS, Rosenberg W, et al. Evidence-based medicine. How to practice and teach EBM. New York: Churchill Livingstone, 1997.

5 Wyer P. The critically appraised topic: closing the evidence-transfer gap. Ann Emerg Med 1997;30:639-40. 